\title{
Overview of the Benefits and Challenges Associated with Pelletizing Biochar
}

\author{
Ali Mohammadi \\ Department of Engineering and Chemical Sciences, Karlstad University, 65188 Karlstad, Sweden; \\ ali.mohammadi@kau.se; Tel.: +46-547-002-480
}

Citation: Mohammadi, A. Overview of the Benefits and Challenges Associated with Pelletizing Biochar. Processes 2021, 9, 1591. https:// doi.org/10.3390/pr9091591

Academic Editors: Carmen Branca and Jingyu Ran

Received: 20 July 2021

Accepted: 2 September 2021

Published: 5 September 2021

Publisher's Note: MDPI stays neutral with regard to jurisdictional claims in published maps and institutional affiliations.

Copyright: (C) 2021 by the author. Licensee MDPI, Basel, Switzerland. This article is an open access article distributed under the terms and conditions of the Creative Commons Attribution (CC BY) license (https:// creativecommons.org/licenses/by/ $4.0 /$ )

\begin{abstract}
Biochar can be derived from a wide variety of organic materials including agricultural wastes and residues, animal wastes, municipal solid wastes, pulp and paper mill wastes, and sewage sludge. Its productivity relies on feedstock type and thermochemical conditions of production. Biochar has many application advantages in several fields and has been widely studied in recent years. However, most of these studies are mainly on the powder form of biochar, while its pelleted form is sparsely reported. Even with the reported studies on biochar pellets, there is still lack of knowledge and awareness of the effects of different feedstock on the densification behavior of biochar. The mechanisms of biochar densification, which appear to be sensitive to the conditions predominating during its thermochemical production, are affected by the material from which the biochar is derived. This partly accounts for why biochar pellets have not been widely adopted in various application fields. Therefore, this paper presents an overview of the benefits associated with the use of biochar pellets and discusses the challenges encountered when pelleting biochars that are derived from different feedstock under various carbonization conditions. Research priority areas needed to overcome the challenges are also identified and discussed. The purpose is to contribute to better understanding on biochar pelletization behavior, and to offer insights useful to comprehend some basic principles that may occur in the pelleting process and to ease further and more thorough investigations.
\end{abstract}

Keywords: attractive forces; compressive pressure; densification; durability; temperature

\section{Introduction}

The Intergovernmental Panel on Climate Change (IPCC) recently recognized biochar as a carbon neutral material that can be used to tackle the issue of climate change [1]. Biochar is a charred material rich in carbon and which can be produced from a wide variety of materials (including agricultural wastes and residues, municipal solid wastes, pulp and paper mill wastes, organic wastes, and sewage sludge) through modern thermochemical technologies such as hydrothermal carbonization, combustion, gasification, pyrolysis, and torrefaction [2]. The yield and quality of the produced biochar vary considerably with the technology used in its production and the process parameters of such technology, which also influences its various application performances [3]. Biochar has a broad range of applications including being used as a soil nutritional and liming agent, as construction material, as an adsorbent for wastewater treatment, or as a source of energy. The environmental and economic benefits from the use of biochar have been reported in recent studies [4-6]. However, in the midst of these numerous application potentials of biochar, challenges abound. Firstly, biochar is dusty with low mechanical strength, which constitutes an issue of concern, especially when it is used in agricultural soils as substantial amounts are often lost to wind or rainfall under soil application conditions. Losses could also result from handling, transportation, and storage. In fact, it has been reported $[7,8]$ that up to $30 \%$ of the quantity of residual biochar could be lost through handling, transportation, and storage; about $25 \%$ is lost during and after field applications, while around $20 \%$ and $53 \%$ is lost 
through intense rainfall. Secondly, because of its fine-textured characteristic, biochar cannot be used in combined heat and power (CHP) plants for the production of energy as it would be difficult to achieve even feed distribution in terms of the quantity of biochar fed into thermal energy systems during energy production. For optimum energy production efficiency, feedstock with regular shape and size is often required [9]. However, these challenges could be addressed by mechanically compressing residual biochar into pellets in such a way that the pelletized biochar would be characterized by uniform shape and size, and will guarantee its economical transportation, distribution, and storage. In addition, pelletized biochar displays increased bulk and energy densities as well as improved carbon content with a substantial reduction in dust recalcitrance as compared to residual biochar [10,11]. These advantages are further discussed in subsequent sections of this paper.

A process diagram illustrating the production, densification, and characterization recommended to produce quality biochar pellet is presented in Figure 1.

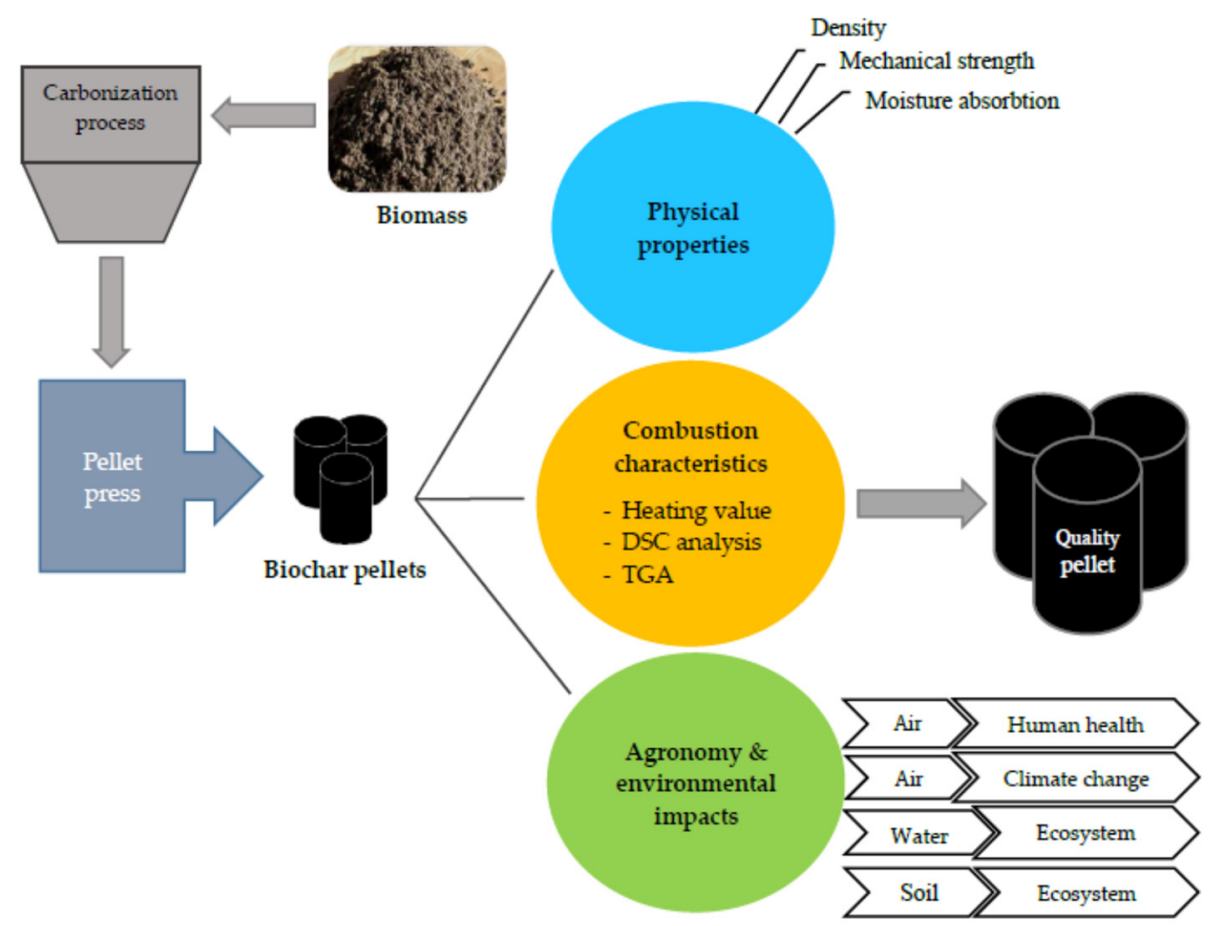

Figure 1. A process flow diagram showing the carbonization, pelletization, and characterization to produce quality biochar pellet from biomass (TGA: thermogravimetric analysis, DSC: differential scanning calorimetry).

Biochar pellets are produced by compacting residual biochar into homogeneouslysized solid fuel with or without a binder via the application of mechanical force $[12,13]$. Although the advantages of using biochar pellets in various fields is well documented and the pelletization of biochars that are derived from a wide range of biomass materials has been attempted and investigated in recent times [14-20], there is limited information on the challenges of the biochar pellet production process as not all materials are suitable for pelletization given the fact that the characteristics of biomass materials vary widely and therefore affect their performance in many conversion processes. The purpose of this review therefore was to contribute to scientific knowledge by describing the benefits and challenges associated with pelleting biochars that are derived from highly recalcitrant biomass materials under carbonization conditions and help identify research priority areas needed to overcome the challenges. 


\section{Biochar Feedstock}

The characteristics of residual biochar are largely influenced by the biomass feedstock used during its thermochemical production and the conditions of production as the elemental composition and surface chemistry of the biochar are usually affected [21,22]. This means that different biomass feedstocks will result in different degrees of surface area, pore sizes, and functional groups in biochar [23]. The densification or pelletization behavior of residual biochar under standard conditions is affected by this alteration in characteristics. For example, biochar produced from animal waste often has specific pore surface area that is much lower than biochar obtained from the plant at same thermochemical production condition and residence time as a result of higher amounts of ash and inorganic compositions in most biochar that are generated from animal dung [24,25]. This low pore surface area could totally varnish upon compression under the pellet press. However, for soil application purposes, biochar pore size and surface area are important in allowing sorption of dissolved organic matter and improving microbial activities, which speeds up remediation of soil organic pollutants; while for application as a source of energy, less porous biochar pellets are more suitable as they tend to have higher ignition propensity [26,27].

Depending on the thermochemical technology used during biochar production and the processing conditions of such technology, some materials (like a host of agricultural residues with low lignin contents) may require the addition of binders to create conditions that will allow the formation of attractive forces that can improve inter-particle bonding during densification. Other materials like pulp and paper mill sludge-derived biochar may not respond to densification under any conditions of the densification process when the biochar from this material is produced with temperatures beyond $500{ }^{\circ} \mathrm{C}$ [28]. Under this temperature condition of biochar production from sludge, even the addition of different ratios of binders such as lignin and wood ash will not bring about the much-needed bonding between particles.

\section{Overview of the Benefits of Biochar Pellets}

Biochar-derived pellets have the same application advantages as residual biochar and the benefits of their application are well established. A very unique advantage of biochar pellets is that, unlike biomass pellets which are mainly used as solid fuels, they (biochar pellets) can be used both as an alternative to biomass pellets for energy production, and as soil conditioning and liming agents. As in the case of pelletization of biomass, biochar pelletization generally results in an increase in the mechanical strength, durability, and density of the produced pellets [29-31]. These properties particularly support any desired applications of the biochar pellets. A more detailed list of the various applications of biochar can be found in [32-34]. As an alternative to biomass pellets, the use of biochar pellets is considered more environmentally friendly because pollutant emissions are less prevalent in comparison to the use of raw biomass pellets [35,36]. Biochar pellets are more hydrophobic and easily friable; hence they exhibit better combustion characteristics when compared to raw biomass pellets [37]. Producing biochar through hydrothermal carbonization (HTC) process and pelletizing the corresponding biochar also improves its heating value relative to the raw biomass pellets due to the higher carbon content in the biochar [38]. This is an important quality parameter when the pellets are considered for use as a source of energy. Some feedstocks such as paper mill sludge or sewage sludge have high content of heavy metals, and there are environmental challenges on their end-of-life handling treatments. Biochar production from these contaminated materials and converting them into pellet can immobilize the heavy metals in biochar due to the transformed chemical forms of heavy metals after carbonization process [39]. This would decrease the leachable fraction of heavy metals from biochar compared to the raw feedstock which leads to significant reduction in toxicity and environmental impacts [40,41].

In summary, pelleted biochar offers the following benefits:

- $\quad$ Easy handling and transport to nursery and forest sites 
- Improved total porosity and aeration porosity in containers (highly desired attributes and their proper balance are essential for optimum seedling growth)

- $\quad$ Reduced nuisance dust and its non-uniform distribution in small-volume containers

- Less nutrient and heavy metal leaching from the pellets.

\section{The Principle of the Densification Process}

It is important to mention that densification and pelletization have been used interchangeably throughout this paper. The densification of residual biochar to pellets is possible from the combined effects of the roller pressure and the back pressure generated by the friction between the compressed material and the walls of the channels [42]. A schematic representation of the process of densification is presented in Figure 2.

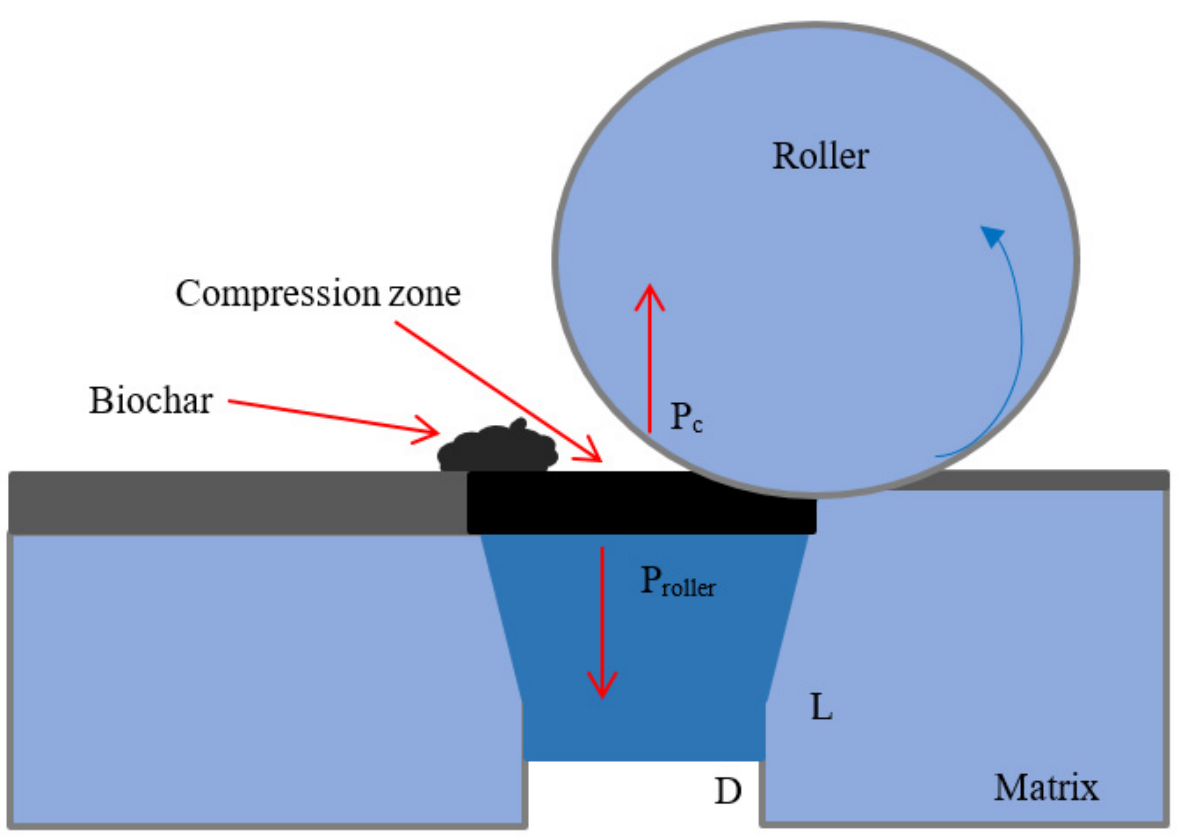

Figure 2. The principle of the process of pelletization with rotating and fixed matrix. $\mathrm{D}$ and $\mathrm{L}$ are the diameter and length of the die, while $P_{\text {roller }}$ and $P_{C}$ respectively represents the pressure generated by the roller on the pelletized biochar, and the compressive pressure of the pelleting process. Reproduced with permission from [14].

The forces acting along the die channel are the main focus of the schematic illustration of the densification process presented in Figure 2. The compressive pressure, Pc, is one pelleting process parameter directly related to the forces acting along the die channel and which is critical in evaluating the feasibility of the pelletization process [14]. The compaction of ground materials during pelletization has been attributed to both elastic and plastic deformation of particles of the ground material at higher compressive pressures [43-45]. Due to the variable conditions under which biochar is produced, and the wide variability in the characteristics of biochar feedstocks, residual biochar particles will behave differently under various applied pressures. As such, it is important to investigate the change in density with pelleting pressures for different biochar feedstocks. This is because the ability of particles to form pellets with increased mechanical strength and the ability to increase density in the process are considered the two vital aspects of the pelletization process [43-45]. By its definition, a reduction of pelleting process pressure would mean a direct relationship with a decrease in the overall energy consumption that is needed in the compaction phase of the pelleting process [46]. Therefore, an investigation of the variation of this factor with the major densification parameters can offer essential information on the feasibility of pelleting biochars that are produced from the combined effects of high temperature production conditions and undesirable material characteristics. 


\section{Challenges of Pelletizing Biochars Derived from Highly Recalcitrant Materials}

Just like raw biomass pellets, the quality of biochar pellets is usually assessed on the basis of its density and durability, which are mostly determined by the strength of the bonds between particles; these quality indicators are influenced by the characteristics of the material used in the production of biochar and the pelleting process variables like die diameter, temperature, and pressure [14]. As previously mentioned, biochar can be produced from a broad range of biomass materials via a number of modern thermochemical processes such as those previously mentioned. However, not all of the materials can be suitably compacted into pellets under charred conditions. For example, pulp and paper mill sludge contains a variety of organic and inorganic substances and becomes sticky when subjected to drying $[47,48]$. This undesirable sticky property has the tendency to create technical issues during thermal conversion of sludge or even during compression into pellets. The recalcitrant nature of sludge was exhibited in a recent unpublished study [28] where the physicochemical characteristics of two types of sludge-derived biochar pellets (hydrochar and pyrochar) that were obtained via hydrothermal carbonization (HTC) and pyrolysis processes were compared. While the hydrochar produced from the HTC process was successfully compressed into uniformly sized pellets by adding varying percentages of wood ash and lignin in the range $0-50 \%$, the pyrochar derived from the pyrolysis process failed to be compressed into pellets, even after adding varying percentages of binders (wood ash and lignin). The most logical reason that could be offered for the failure in pelletizing pyrochar was that the residual pyrochar was produced at high pyrolysis temperature greater than $500{ }^{\circ} \mathrm{C}$. Under this high production temperature, it was assumed that most of the material's organic matter had completely degraded, rendering the pyrochar too brittle and flaky to be successfully compressed into pellets. The images of the pyrochar in question are presented in Figure 3.
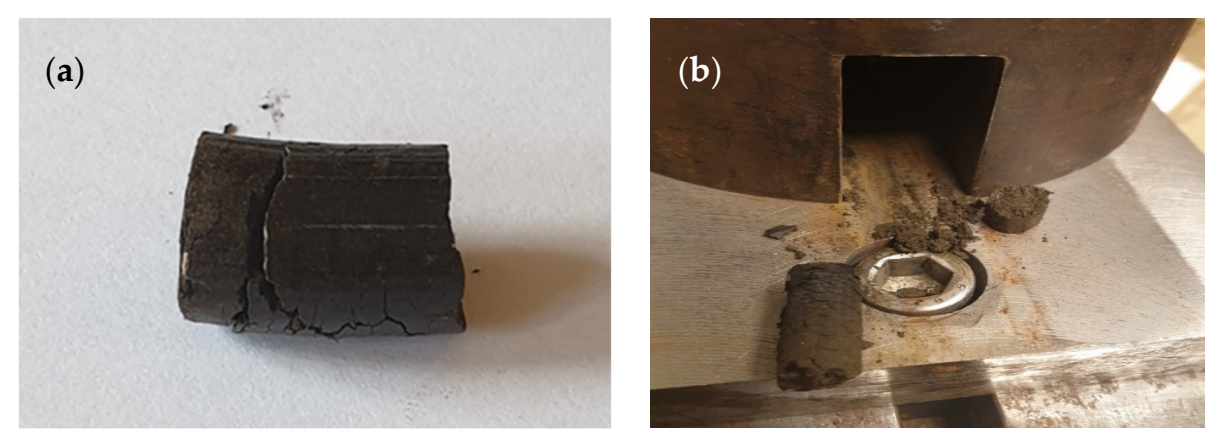

Figure 3. Sludge-derived pyrochar pellets containing equal amounts of wood ash and lignin as binders: (a) cracked pellet; (b) disintegrated pellet exiting from the opening of the press channel.

The charcoals obtained from HTC and pyrolysis processes are often referred to as hydrochar and pyrochar, respectively. These two charred carbon-rich materials are considered types of biochar. Other benefits of incorporating pelleted biochar into agricultural and forest soils have been reported by many researchers [49]. Improved soil structure, enhanced water-holding capacity, nutrient sorption and release, as well as increased soil carbon storage capacity have all been reported. However, a good number of the soils in Sweden are acidic and the addition of biochar pellets into these soils can raise the $\mathrm{pH}$ of the soil due to the alkaline properties of biochar, which in turn increases agriculture and forest productivity [50]. Pulp and paper mill wastewater sludge also contains large amounts of heavy metals; therefore, using sludge for biochar production and subsequently compressing the biochar into pellets with regular shape and size can substantially reduce bioavailability and eco-toxicity of heavy metals due to transformation in the chemical compositions of the metals during the process of carbonization and pelletization [39,41]. Pyrolysis is a promising sludge treatment method for heavy metals immobilization [51]. 
However, the pelleting behavior of sludge produced under pyrolysis conditions needs to be further investigated.

\section{The Role of Functional Groups in Biochar Densification}

Functional groups are important to organic materials as they confer specific characteristics that often determine the performance of the materials in conversion processes. A higher amount of polar functional groups is an indication of stronger electrostatic force of attraction that includes hydrogen bonding and van der Waal's attraction forces [52]. This is because hydrogen bonding, for instance, is characterized by increased bond strength that is in the range $2.5-120 \mathrm{kj} / \mathrm{mol}$, with variation in bond length between 0.12 and $0.32 \mathrm{~nm}$ depending on its bond strength; as such, compressing biochar particles up to a distance of about $0.32 \mathrm{~nm}$ will lead to the formation of hydrogen bonding due to the presence of polar functional groups on the surface, particularly oxygen-containing groups [53-55].

In view of the above functional group theory, there is a need to investigate the effects of densification on inter-particle distance and bond evolution when pelletizing biochars that are produced from highly recalcitrant materials such as pulp and paper mill sludge under pyrolysis conditions.

\section{Pelletizing Pyrochar Derived from Pulp and Paper Mill Sludge}

Although the challenges of pelletizing sludge-derived pyrochar had been briefly described in a previous section, it is necessary to elaborate more on the difficulties in order to guide future attempts of compressing sludge-derived pyrochar into pellets. As a byproduct of pulp and paper mill operations, sludge is a type of abundant waste containing large amounts of organic substances, with protein being its major organic fraction [56]. In terms of composition, proteins consist of amino acid chains that are held together by peptide bonds, which are mostly covalent in nature. Under high temperature conditions, these bonds are broken because the carbonyl carbon present in the bonds is attacked by electronegative atoms that will allow the formation of small tetrahedral molecules. The peptide fractions and amino acids derived from the breaking down of protein further degrade to low molecular weight substances via decarboxylation reactions, initiating the formation of $\mathrm{CO}_{2}$. Under these set of circumstances, the concentrations of hydroxide ions will decrease rapidly due to moisture evaporation and will significantly affect the aromatic features of pyrochar. These conditions may explain the brittle, flaky, and friable nature of residual pyrochar obtained from the high pyrolysis process temperature of sludge. This is because the textural properties mentioned above renders particles less likely to form attraction forces under mechanical compression. A more logical explanation is that due to its textural properties, the pyrochar will likely break into small heterogeneous particles under applied compressive force during pelletization.

According to literature reports $[29,57]$, certain materials that are subjected to pyrolysis conditions will have different characteristics (such as increased friability, enhanced surface area, and pore structure) that may invariably alter their pellet-forming abilities; this alteration in characteristics may impede particle deformation and lower particle adherence to each other, making it difficult to form pellets in the process. However, as previously indicated, the conditions described are certainly different among various biomass materials. For instance, it may be much easier to compress pyrochar produced from lignocellulosic biomass such as wood under the same pyrolysis temperature as that mentioned for sludge in a previous section. This is because lignocellulosic materials are mainly composed of three major biopolymers (cellulose, hemicellulose, and lignin) with varied structural properties that are different from the components of sludge.

\section{Pelletizing Pyrochar Derived from Lignocellulosic Biomass}

The biopolymers of lignocellulosic materials are much more compression-responsive relative to those of sludge, although this may depend on the pyrolysis temperature at which pyrochar may be produced from the lignocellulosics. Riva et al. 2021 [14] suggested 
that to facilitate the densification of lignocellulosic materials such as Pine wood, it is necessary to pyrolyze the wood at relatively high temperatures (between 400 and $800{ }^{\circ} \mathrm{C}$, respectively). For the pyrolysis of the lignocellulosics under high temperature conditions, depolymerization of their main biopolymers (cellulose, hemicellulose, and lignin) occurs in such a way that the respective biopolymers are degraded into their monomeric units with the formation of water and other substances like the p-cumaryl alcohol, coniferyl alcohol, and synapyl alcohol that are mostly associated with lignin; these lignin monomer units facilitate inter-particle bonding under high temperature and compression conditions [58,59]. There have been other studies conducted with the aim of investigating the pelleting behavior of biochar derived from a pyrolysis process of other biomass materials. One such study was undertaken by Bazargan et al., 2014 [60] who reported that compacting palm kernel shell-derived pyrochar without adding water results in weak inter-particle bonding. Studies [61] have also shown that lignin can be used to facilitate bonding between particles when pelletizing sawdust-derived pyrochar to obtain durable pellets that are resistant to moisture.

Biochar production from a pyrolysis process has been the main subject of discussion because pyrolysis occurs at relatively high temperatures (500-800 ${ }^{\circ} \mathrm{C}$ ) [62] and at different scales [63] as compared to other thermochemical processes such as HTC and torrefaction, which are characterized by much lower temperature ranges $\left(200-300{ }^{\circ} \mathrm{C}\right)$. Biochar recalcitrance increases with increasing temperature of pyrolysis as studies [14,64] have determined that the pelletization of biochars produced at high temperature pyrolysis conditions of around $400{ }^{\circ} \mathrm{C}$ is particularly challenging.

\section{Biochar Pelletizing Methods}

Most experimental investigations involving biochar pelleting have been conducted using the single pellet press channel technique. Continuous production of biochar pellets on a large-scale with mass flow of up to $50 \mathrm{~kg} / \mathrm{h}$ is sparsely tested and could constitute a novel and practical approach that could facilitate wider adoption of biochar pellets in various application fields. A summary of previous studies on the pelleting of biochars that are derived from different feedstocks and the pelletizing methods used are presented in Table 1.

Table 1. List of published papers presenting recent methods for pelletizing biochar produced from different biomass feedstocks.

\begin{tabular}{|c|c|c|c|c|c|c|}
\hline Reference & $\begin{array}{l}\text { Country } \\
\text { (Region) }\end{array}$ & $\begin{array}{l}\text { Feedstock for } \\
\text { Biochar }\end{array}$ & $\begin{array}{c}\text { Carbonization } \\
\text { Technology }\end{array}$ & Binder & Water Added & Pellet Technology \\
\hline [10] & China & Rice husk & Pyrolysis & $\begin{array}{l}\text { Lignin, starch, } \\
\mathrm{Ca}(\mathrm{OH})_{2}, \mathrm{NaOH}\end{array}$ & $5-20 \%$ & $\begin{array}{c}\text { Universal material testing } \\
\text { machine (CMT5205, } \\
\text { MTS, China) }\end{array}$ \\
\hline [11] & China & Corn straw & Pyrolysis & - & - & (VIS, \\
\hline [16] & Norway-Italy & Pine wood & Pyrolysis & Pyrolysis oil & 33.9 & $\begin{array}{c}\text { Compact hot pellet press } \\
\text { (MTI, USA) }\end{array}$ \\
\hline [20] & China & Woody shavings & Pyrolysis & Lignin & $35 \%$ & $\begin{array}{l}\text { Universal material testing } \\
\text { machine (CMT5205, } \\
\text { MTS, China) }\end{array}$ \\
\hline [31] & USA & Pine wood & HTC & - & - & Single pellet machine \\
\hline [37] & China & $\begin{array}{l}\text { Cotton stalk } \\
\text { Pinewood sawdust, }\end{array}$ & HTC & - & $20 \%$ & Single pellet machine \\
\hline [38] & Singapore & $\begin{array}{l}\text { rice husk } \\
\text { coconut residues }\end{array}$ & HTC & - & - & Single pellet machine \\
\hline [61] & China & Spruce wood sawdust & Pyrolysis & $\begin{array}{c}\text { Lignin, } \mathrm{Ca}(\mathrm{OH})_{2} \\
\mathrm{NaOH}, \mathrm{CaCl}_{2}, \mathrm{CaO}\end{array}$ & $0-20 \%$ & $\begin{array}{l}\text { Hydraulic press powder } \\
\text { pelletizer (HuaiYu } \\
\text { Tianjin, China) }\end{array}$ \\
\hline
\end{tabular}

It is important to mention that lab-scale investigations of the pelleting behavior of biochar can facilitate the feasibility study of large-scale biochar pelleting processes. However, achieving the desired pellet quality in terms of strength and durability under large-scale production conditions can be quite challenging. In fact, it is almost impossible to pelletize biochar on an industrial scale without the use of additives or binders and a 
proper moisture content optimization. The following constitute important points in the biochar densification process:

- For biochar produced under pyrolysis process conditions (pyrochar), a binder is required for the pelletization of the biochar. A few studies [16,27] used pyrolysis oil as binder and moisture in densification process and reported the mechanical properties of biochar pellets blended with pyrolysis oil enhanced considerably.

- $\quad$ For biochar produced from a HTC process (hydrochar), the use of an external binder may not be required as lignin in hydrochar act as a viable natural binder during pelletization. The nature of lignin at temperatures below $260{ }^{\circ} \mathrm{C}$ is not influenced during HTC process [31].

- Moisture plays a very important role in pelletization since moisture can simultaneously act as a binder and lubricant [14]. However, depending on the type of biochar feedstock and carbonization technology, some quantities of water may be added to the mixtures at different mass ratios and homogenized by a magnetic stirrer prior to pelletization.

- Practical biochar pelleting steps using appropriate pellet press involve drying, grinding, addition of binders and water, stirring, compression, cooling, and storage.

However, pelletizing biochar for different applications is at the early-stage of research and therefore further studies may be required to determine and compare the chemical and physical properties of biochar pellets generated from different materials. Moreover, the influence of significant factors during carbonization process (e.g., pyrolysis temperature and residence time) and technical parameters during densification process (e.g., compressive force, holding time and the speed of girder moving) on the quality of biochar pellets need to be further investigated.

\section{Conclusions and Research Priorities}

This review intended to contribute to better understanding of the mechanism behind biochar densification, its benefits and challenges, offering non-exhaustive insights useful to comprehend some fundamental phenomena that are likely to occur when pelleting biochars that are derived from highly recalcitrant materials under high temperature conditions such as those from a pyrolysis process. For extended knowledge of biochar pelletization process and the impacts of specific parameters, there is a need to develop models that will provide information about the pelleting behavior of biochar in relation to changes in key pelleting parameters like temperature and compression force, particularly for biochars produced under high temperature pyrolysis conditions from materials with complex characteristics like pulp and paper mill sludge. The developed model must also be used to validate the densification of biochars that are derived from different materials. Such a model must be further optimized and simplified. This preliminary lab-scale evaluation can facilitate the feasibility study of industrial level biochar pelletization processes. Furthermore, although biochar pellets may offer several benefits, a few concerns still exist. Novel and practical biochar pelletizing methods and frameworks are still to be achieved in the field of biochar densification research, which constitutes a basis for further studies.

Biochar pellets can offer the benefits of enhancing soil nutrient status and crop growth as well as decreasing $\mathrm{N}_{2} \mathrm{O}$ emissions including being a potential source of energy. However, the explanations related to these benefits has not been adequately described, particularly when the biochar pellets have been derived from materials with high inorganic composition such as pulp and paper mill wastewater sludge. Therefore, soil-biochar pellets and energy production-biochar pellets dynamics need to be carefully investigated to deliver understanding in these and several other areas. The basic mechanisms by which pelleted biochar affects soil function and the wider agro-economic system is poorly defined; as such, current capacity to foretell the impacts of pelleted biochar is exiguous, even in the event that the biochar pellets are used as a source of energy. Until research provides the tools needed to advance the application function of biochar pellets, its widespread adoption as an alternative to its fine-textured and dusty form may be hindered. 
Funding: This study was funded by ÅForsk in Sweden with grant number "19-622".

Institutional Review Board Statement: Not applicable.

Informed Consent Statement: Not applicable.

Data Availability Statement: Not applicable.

Conflicts of Interest: The authors declare no conflict of interest.

\section{References}

1. Intergovernmental Panel on Climate Change. Global Warming of $1.5^{\circ} \mathrm{C}$ Report; Intergovernmental Panel on climate change: Geneva, Switzerland, 2019.

2. Sakhiya, A.K.; Anand, A.; Kaushal, P. Production, activation, and applications of biochar in recent times. Biochar 2020, 2, $253-285$. [CrossRef]

3. Wang, D.; Jiang, P.; Zhang, H.; Yuan, W. Biochar production and applications in agro and forestry systems: A review. Sci. Total Environ. 2020, 723, 137775. [CrossRef] [PubMed]

4. Mohammadi, A.; Khoshnevisan, B.; Venkatesh, G.; Eskandari, S. A critical review on advancement and challenges of biochar application in paddy fields: Environmental and life cycle cost analysis. Processes 2020, 8, 1275. [CrossRef]

5. Sahoo, K.; Upadhyay, A.; Runge, T.; Bergman, R.; Puettmann, M.; Bilek, E. Life-Cycle Assessment and Techno-Economic Analysis of Biochar Produced from Forest Residues Using Portable Systems. Int. J. Life Cycle Assess. 2021, 26, 189-213. [CrossRef]

6. Mohammadi, A.; Cowie, A.; Cacho, O.; Kristiansen, P.; Anh Mai, T.L.; Joseph, S. Biochar addition in rice farming systems: Economic and energy benefits. Energy 2017, 140, 415-425. [CrossRef]

7. Major, J.; Lehmann, J.; Rondon, M.; Goodale, C. Fate of soil-applied black carbon: Downward migration, leaching and soil respiration. Glob. Chang. Biol. 2010, 16, 1366-1379. [CrossRef]

8. Husk, B.; Major, J. Commercial Scale Agricultural Biochar Field Trial in Quebec, Canada, Over Two Years: Effects of Biochar on Soil Fertility, Biology, Crop Productivity and Quality; Blue Leaf Incorporated: Drummondville, QC, Canada, 2008.

9. Kataki, R.; Chutia, S.R.; Mishra, M.; Bordoloi, N.; Saikia, R.; Bhaskar, T. Feedstock suitability for thermochemical processes. In Recent Advances in Thermo-Chemical Conversion of Biomass, 1st ed.; Pandey, A., Bhaskar, T., Stöcker, M., Sukumaran, R., Eds.; Elsevier: Amsterdam, The Netherlands, 2015; pp. 31-74.

10. Hu, Q.; Shao, J.; Yang, H.; Yao, D.; Wang, X.; Chen, H. Effects of binders on the properties of bio-char pellets. Appl. Energy 2015, 157, 508-516. [CrossRef]

11. Xing, X.; Fan, F.; Jiang, W. Characteristics of biochar pellets from corn straw under different pyrolysis temperatures. R. Soc. Open Sci. 2018, 5, 172346. [CrossRef]

12. Roy, M.M.; Corscadden, K.W. An experimental study of combustion and emissions of biomass briquettes in a domestic wood stove. Appl. Energy 2012, 99, 206-212. [CrossRef]

13. Li, H.; Jiang, L.-B.; Li, C.-Z.; Liang, J.; Yuan, X.-Z.; Xiao, Z.-H.; Xiao, Z.-H.; Wang, H. Co-pelletization of sewage sludge and biomass: The energy input and properties of pellets. Fuel Process. Technol. 2015, 132, 55-61. [CrossRef]

14. Riva, L.; Wang, L.; Ravenni, G.; Bartocci, P.; Buø, T.V.; Skreiberg, Ø.; Fantozzi, F.; Nielsen, H.K. Considerations on factors affecting biochar densification behaviour based on a multiparameter model. Energy 2021, 221, 119893. [CrossRef]

15. Riva, L.; Surup, G.R.; Buø, T.V.; Nielsen, H.K. A study of densified biochar as carbon source in the silicon and ferrosilicon production. Energy 2019, 181, 985-996. [CrossRef]

16. Riva, L.; Nielsen, H.K.; Skreiberg, Ø.; Wang, L.; Bartocci, P.; Barbanera, M.; Bidini, G.; Fantozzi, F. Analysis of optimal temperature, pressure and binder quantity for the production of biocarbon pellet to be used as a substitute for coke. Appl. Energy 2019, 256, 113933. [CrossRef]

17. Wang, L.; Buvarp, F.; Skreiberg, Ø.; Bartocci, P. A study on densification and $\mathrm{CO}_{2}$ gasification of biocarbon. Chem. Eng. Trans. 2018, 65, 145-150.

18. Kang, K.; Zhu, M.; Sun, G.; Qiu, L.; Guo, X.; Meda, V.; Sun, R. Codensification of Eucommia ulmoides Oliver stem with pyrolysis oil and char for solid biofuel: An optimization and characterization study. Appl. Energy 2018, 223, 347-357. [CrossRef]

19. Bartocci, P.; Barbanera, M.; Skreiberg, Ø.; Wang, L.; Bidini, G.; Fantozzi, F. Biocarbon pellet production: Optimization of pelletizing process. Chem. Eng. Trans. 2018, 65, 355-360.

20. Hu, Q.; Yang, H.; Yao, D.; Zhu, D.; Wang, X.; Shao, J.; Chen, H. The densification of bio-char: Effect of pyrolysis temperature on the qualities of pellets. Bioresour. Technol. 2016, 200, 521-527. [CrossRef]

21. Colantoni, A.; Evic, N.; Lord, R.; Retschitzegger, S.; Proto, A.R.; Gallucci, F.; Monarca, D. Characterization of biochars produced from pyrolysis of pelletized agricultural residues. Renew. Sustain. Energy Rev. 2016, 64, 187-194. [CrossRef]

22. Sun, K.; Jin, M.; Keiluweit, M.; Kleber, Z.; Wang, Z.; Pan, B.; Xing, B. Polar and aliphatic domains regulate sorption of phthalic acid esters (PAEs) to biochar. Bioresour. Technol. 2012, 118, 120-127. [CrossRef]

23. Sohi, S.; Wade, S.C.; Kern, J. Consistency of biochar properties over time and production scales: A characterisation of standard materials. J. Anal. Appl. Pyrolysis 2017, 132, 200-210.

24. Ok, Y.S.; Chang, S.X.; Gao, B.; Chung, H.-J. SMART biochar technology-A shifting paradigm towards advanced materials and healthcare research. Environ. Technol. Innov. 2015, 4, 206-209. [CrossRef] 
25. Singh, B.P.; Cowie, A.L.; Smernik, R.J. Biochar carbon stability in a clayey soil as a function of feedstock and pyrolysis temperature. Environ. Sci. Technol. 2012, 46, 11770-11778. [CrossRef] [PubMed]

26. Hameed, A.; Hussain, S.A.; Yang, J.; Ijaz, M.U.; Liu, Q.; Suleria, H.A.R.; Song, Y. Antioxidants potential of the filamentous fungi (Mucor circinelloides). Nutrients 2017, 9, 1101. [CrossRef]

27. Riva, L.; Cardarelli, A.; Andersen, G.J.; Buø, T.V.; Barbanera, M.; Bartocci, P.; Fantozzi, F.; Nielsen, H.K. On the self-heating behavior of upgraded biochar pellets blended with pyrolysis oil: Effects of process parameters. Fuel 2020, 278, 118395. [CrossRef]

28. Mohammadi, A. Biochar Pellets, a Soil Nutritional and Liming Agent or a Source of Energy: Effects of Ash and Lignin on the Physical and Chemical Properties; ÅForsk Foundation: Stockholm, Sweden, 2021.

29. Abdullah, H.; Wu, H. Biochar as a fuel: Properties and grindability of biochars produced from the pyrolysis of mallee wood under slow-heating conditions. Energy Fuels 2009, 23, 4174-4181. [CrossRef]

30. Stelte, W.; Sanadi, A.R.; Shang, L.; Holm, J.K.; Ahrenfeldt, J.; Henriksen, U.B. Recent developments in biomass palletization-A review. BioResources 2012, 7, 4451-4490. [CrossRef]

31. Reza, T.M.; Lynam, J.G.; Vasquez, V.R.; Coronella, C.J. Pelletization of biochar from hydrothermally carbonized wood. Environ. Prog. Sustain. Energy 2012, 31, 225-234. [CrossRef]

32. Mohammadi, A.; Venkatesh, G.; Sandberg, M.; Eskandari, S.; Joseph, S.; Granström, K. A Comprehensive Environmental Life Cycle Assessment of the Use of Hydrochar Pellets in Combined Heat and Power Plants. Sustainability 2020, 12, 9026. [CrossRef]

33. Zhang, Z.; Zhu, Z.; Shen, B.; Liu, L. Insights into biochar and hydrochar production and applications: A review. Energy 2019, 171, 581-598. [CrossRef]

34. Eskandari, S.; Mohammadi, A.; Sandberg, M.; Eckstein, R.L.; Hedberg, K.; Granström, K. HydrocharAmended Substrates for Production of Containerized Pine Tree Seedlings under Different Fertilization Regimes. Agronomy 2019, 9, 350. [CrossRef]

35. Mladenovic, M.; Paprika, M.; Marinkovic, A. Denitrification techniques for biomass combustion. Renew. Sustain. Energy Rev. 2018, 82, 3350-3364. [CrossRef]

36. Yin, C.Y. Prediction of higher heating values of biomass from proximate and ultimate analyses. Fuel 2011, 90, 1128-1132. [CrossRef]

37. Zhu, G.; Yang, L.; Gao, Y.; Xu, J.; Chen, H.; Zhu, Y.; Wang, Y.; Liao, C.; Lu, C.; Zhu, C. Characterization and pelletization of cotton stalk hydrochar from HTC and combustion kinetics of hydrochar pellets by TGA. Fuel 2019, 244, 479-491. [CrossRef]

38. Liu, Z.; Quek, A.; Balasubramanian, R. Preparation and characterization of fuel pellets from woody biomass, agro-residues and their corresponding hydrochars. Appl. Energy 2014, 113, 1315-1322. [CrossRef]

39. Chen, H.; Zhou, Y.; Zhao, H.; Li, Q. A comparative study on behavior of heavy metals in pyrochar and hydrochar from sewage sludge. Energy Sources Part A Recovery Util. Environ. Eff. 2018, 40, 565-571. [CrossRef]

40. Mohammadi, A.; Sandberg, M.; Venkatesh, G.; Eskandari, S.; Dalgaard, T.; Joseph, S.; Granström, K. Environmental performance of end-of-life handling alternatives for paper-and-pulp-mill sludge: Using digestate as a source of energy or for biochar production. Energy 2019, 182, 594-605. [CrossRef]

41. Mohammadi, A.; Sandberg, M.; Venkatesh, G.; Eskandari, S.; Dalgaard, T.; Joseph, S.; Granström, K. Environmental analysis of producing biochar and energy recovery from pulp and paper mill biosludge. J. Ind. Ecol. 2019, 23, 1039-1051. [CrossRef]

42. Holm, J.K.; Stelte, W.; Posselt, D.; Ahrenfeldt, J.; Henriksen, U.B. Optimization of a multiparameter model for biomass pelletization to investigate temperature dependence and to facilitate fast testing of pelletization behavior. Energy Fuels 2011, 25, 3706-3711. [CrossRef]

43. Tabil, L.G. Binding and Pelleting Characteristics of Alfalfa. Ph.D. Thesis, University of Saskatchewan, Saskatchewan, SK, Canada, 1996.

44. Tabil, L.G.; Sokhansanj, S. Compression and compaction behavior of alfalfa grinds, Part 1: Compression behavior. Powder Hand. Process. 1996, 8, 17-23.

45. Tabil, L.G.; Sokhansanj, S. Compression and compaction behavior of alfalfa grinds, Part 2: Compaction behavior. Powder Hand. Process. 1996, 8, 117-122.

46. Holm, J.K.; Henriksen, U.B.; Hustad, J.E.; Sørensen, L.H. Toward an understanding of controlling parameters in softwood and hardwood pellets production. Energy Fuels 2006, 20, 2686-2694. [CrossRef]

47. Hovey, G.; Allen, D.G.; Tran, H. The sticky behaviour of pulp and paper mill biosludge during drying. Biofuel 2019, 18, 353-359.

48. Lekha, P.; Andrew, J.; Gibril, M.; Sithole, B. Pulp and paper mill sludge: A potential resource for producing high-value products. TAPPSA 2017, 1, 16-19.

49. Li, S.; Barreto, V.; Li, R.; Chen, G.; Hsieh, Y.P. Nitrogen retention of biochar derived from different feedstocks at variable pyrolysis temperatures. J. Anal. Appl. Pyrolysis 2018, 133, 136-146. [CrossRef]

50. Dai, Z.; Zhang, X.; Tang, C.; Muhammad, N.; Wu, J.; Brookes, P.C.; Xu, J. Potential role of biochars in decreasing soil acidificationA critical review. Sci. Total Environ. 2017, 581-582, 601-611. [CrossRef] [PubMed]

51. Mohammadi, A.; Venkatesh, G.; Sandberg, M.; Eskandari, S.; Granström, K. Life cycle assessment of combination of anaerobic digestion and pyrolysis: Focusing on different options for biogas use. Adv. Geosci. 2019, 49, 57-66. [CrossRef]

52. Anukam, A.I.; Berghel, J.; Famewo, E.B.; Frodeson, S. Improving the understanding of the bonding mechanism of primary components of biomass pellets through the use of advanced analytical instruments. J. Wood Chem. Technol. 2020, 40, 15-32. [CrossRef] 
53. Nielsen, N.P.K.; Gardner, D.J.; Felby, C. Effect of extractives and storage on the pelletizing process of sawdust. Fuel 2010, 89, 94-98. [CrossRef]

54. Liu, Z.; Zhang, F.S. Effects of various solvents on the liquefaction of biomass to produce fuels and chemical feedstocks. Energy Convers. Manag. 2008, 49, 3498-3504. [CrossRef]

55. Yan, W.; Acharjee, T.C.; Coronella, C.J.; Vasquez, V.R. Thermal pretreatment of lignocellulosic biomass. Environ. Prog. Sustain. Energy 2009, 28, 435-440. [CrossRef]

56. Gai, C.; Chen, M.; Liu, T.; Peng, N.; Liu, Z. Gasification characteristics of hydrochar and pyrochar derived from sewage sludge. Energy 2016, 113, 957-965. [CrossRef]

57. Chen, Y.; Yang, H.; Wang, X.; Zhang, S.; Chen, H. Biomass-based pyrolytic polygeneration system on cotton stalk pyrolysis: Influence of temperature. Bioresour. Technol. 2012, 7, 411-418. [CrossRef]

58. Stelte, W.; Holm, J.K.; Sanadi, A.R.; Barsberg, S.; Ahrenfeldt, J.; Henriksen, U.B. A study of bonding and failure mechanisms in fuel pellets from different biomass resources. Biomass Bioenergy 2011, 35, 910-918. [CrossRef]

59. Olsson, A.M.; Salmen, L. Viscoelasticity of in situ lignin as affected by structure: Softwood vs. hardwood. In Viscoelasticity of Biomaterials; Glasser, W., Ed.; American Chemical Society: Washington, DC, USA, 1992; pp. 133-143.

60. Bazargan, A.; Rough, S.L.; McKay, G. Compaction of palm kernel shell biochars for application as solid fuel. Biomass Bioenergy 2014, 70, 489-497. [CrossRef]

61. Kong, L.; Tian, S.; Li, Z.; Luo, R.; Chen, D.; Tu, Y.; Xiong, Y. Conversion of recycled sawdust into high HHV and low NOx emission bio-char pellets using lignin and calcium hydroxide blended binders. Renew. Energy 2013, 60, 559-565. [CrossRef]

62. Chatterjee, R.; Sajjadi, B.; Chen, W.-Y.; Mattern, D.L.; Hammer, N.; Raman, V.; Dorris, A. Effect of pyrolysis temperature on physicochemical properties and acoustic-based amination of biochar for efficient $\mathrm{CO}_{2}$ adsorption. Front. Energy Res. $2020,8,85$. [CrossRef]

63. Mohammadi, A.; Cowie, A.L.; Anh Mai, T.L.; Brandão, M.; de la Rosa, R.A.; Kristiansen, P.; Joseph, S. Climate-change and health effects of using rice husk for biochar-compost: Comparing three pyrolysis systems. J. Clean. Prod. 2017, 162, 260-272. [CrossRef]

64. Ulusal, A.; Varol, E.A.; Bruckman, V.J.; Uzun, B.B. Opportunity for sustainable biomass valorization to produce biochar for improving soil characteristics. Biomass Convers. Biorefin. 2021, 11, 1041-1051. [CrossRef] 